highly developed, and the starting point is usually the laws of three-colour mixture. In terms of colorimetry, the reproduction should consist of the appropriate combination of red, green and blue radiations that will, at each point of the picture, match the colour of the original at that point. This provides a working hypothesis from which to derive such items as the theoretical spectral sensitivities of the three light-sensitive processes in the colour camera. For various reasons, major departures from colorimetric theory are both necessary and inevitable, and it is no easy matter to present a comprehensive and comprehensible account of all the factors that ultimately have to be considered. This, however, is in essence the main intention of the book under review and the authors have made a notable and successful contribution in this field.

First, we have chapters dealing with colour matching and colour measurement (those interested in the algebraic representation of these matters will be surprised to find colour equations given in a form which has been generally condemned in the United States although common practice in Great Britain until recently), followed by a discussion of the visual processes of adaptation, contrast and the like, which affect so vitally the subjective appearance of a picture yet are so baffling to express in algebraic or numerical terms. Next, we have chapters on the chemistry of the photographic processes and the optical characteristics of dye mixtures and their measurement, leading naturally to colour sensitometry and the consideration of the $H$ and $D$ characteristics of colour processes. Two chapters dealing with the special cases of duplicating and copying are interpolated, and the final two chapters discuss the generalized theories of additive and subtractive reproduction.

It will be realized that this book is full of weighty material which cannot be described as light reading, yet the text itself is written in a very clear style and is therefore casy to read. The authors are well aware that they have not written the final word on the subject, for their closing paragraphs and indeed the closing sentence emphasize that lack of knowledge of the visual relationship between the photograph and the scene makes it necessary for present-day processes to be worked out empirically. Yet this is an excellent statement of our present understanding of the problem, and no serious workers in colour photography or colour television can afford to ignore it if they wish to reduce the empiricism in their techniques to a minimum.

W. D. WRIGHT

\section{PRESENTING MODERN CHEMISTRY}

\section{General Chemistry}

An Introduction to Descriptive Chemistry and Modern Chemical Theory. By Prof. Linus Pauling. Second edition. Pp. xii $+710+2$ plates. (San Franciseo: W. H. Freeman and Company, 1953.) 6 dollars; $51 s$.

W ${ }^{H E N,}$ at a conference in the United States, 7 Prof. Linus Pauling was asked about his views on the teaching of chemistry he is reported to have said: "One wants to teach that section which inspires and holds a man and which feels alive ; then, moving on to greater and greater triumphs, that which both fascinates and profits mankind. The text-book should contain what the writer really believes and really knows, not the stuff which seems dead and ought to be put into museums". The speech reveals the attitude to teaching in which "General Chemistry" was written and the principles which guided the writer in selecting his material and arranging its sequence. "That which inspires and holds a man ...": the speaker, the grand-master in the field of the ionic bond and of the electronic structure of the molecule, showed in this work how a simple exposition of modern theoretical concepts could, to use his own words, make the presentation of general chemistry "more simple, straightforward and logical than formerly". All who have used modern theory in their teaching will concur. "General Chemistry" rapidly obtained world-wide recognition as belonging to that small class of books, as did the works of W. Ostwald and of Alexander Smith in days gone by, which revolutionized the teaching practice then prevailing and laid down the pattern for future texts.

The first edition was reviewed and commended in Nature (June 26, 1948): its contents are too well known to be again listed; but those yet unacquainted with "General Chemistry" should know that it is an introduction for first-year university students. In this, the second edition, Prof. Pauling gives us further teaching help, for he shows us how he meets the difficult problem of giving an adequate presentation of a science, which, already huge, is expanding in every direction. His plan is to increase the depth of the treatment of theory, especially of those aspects which are pertinent to the explanation of chemical behaviour and which are integrating in their incidence, so that all but the future specialist will have sufficient theory to carry him through his entire chemistry course. At the same time, a new chapter entitled "Biochemistry" extends the breadth of treatment and introduces a humanizing factor. For this chapter is essentially a fascinating essay on proteins, vitamins, drugs and their relation to life and mankind.

Most of the additional theory is in two new chapters, respectively entitled "The Electron and the Nucleus", and "Quantum Theory and Molecular Structure". Among the topics discussed in these chapters are : $\mathrm{X}$-rays, the electron, radioactivity, the atomic nucleus, the quantum theory, the photoelectric effect, the photon, and the changed outlook brought about by quantum mechanics.

The new introductory chapter on metals is not only interesting and inspiring but also illustrates the author's ability to use the electronic theory to explain and systematize the phenomena under discussion. Thus he shows how the increase in the structural strength of successive metals in a Mendeléeff period is dependent upon the electronic configuration of the metal and of the arrangement of its atoms in the crystal. Physical properties are therefore no longer seen as haphazard phenomena but, as with chemical properties, are determined by structure, and are predictable.

The four new chapters, and the revision and frequent extensions of most of the original chapters, enlarge the book by 115 pages. The flashes of understanding which must come from a study of "General Chemistry" and the freshness of approach to the subject-matter make it an excellent text for firstyear university students or for candidates for university scholarships. If not used as a text-book, a copy should bo in every chemical library.

G. Fowles 